\title{
Significant rise of the prevalence and clinical features of childhood asthma in Qingdao China: cluster sampling investigation of 10,082 children
}

\author{
Rongjun Lin ${ }^{*}$, Renzheng Guan ${ }^{1}$, Xiaomei Liu', Baochun Zhao', Jie Guan² and Ling Lu
}

\begin{abstract}
Background: Recent investigations suggested that the trend of childhood asthma has been stabilizing or even reversing in some countries. The observation provides contrast to our experience. Thus, the study aimed to investigate the prevalence and clinical features of asthma in children aged 0-14 years in Qingdao China, determine the changes of childhood asthma in China, and discover evidence that can allow better diagnosis and treatment of childhood asthma.
\end{abstract}

Methods: A cluster sampling method was used. We randomly extracted the investigation clusters from schools, kindergartens, and communities in Qingdao. Subsequently, we interviewed the members of the clusters using a questionnaire from the International Study of Asthma and Allergies in Childhood (ISAAC) to find children with asthmatic symptoms. After determination by the doctors, more details on the asthmatic children were obtained by asking questions from the National Epidemiology Study of Asthma and Allergies in China questionnaire to obtain more details. We intended to survey 10,800 children. However, the actual number of children was 10,082.

Results: The prevalence of asthma in Qingdao children aged 0-14 years was 3.69\%. The prevalence among male children was higher than in female $(x 2=24.53, P<0.01)$. Among the asthmatic children, $68.0 \%$ had their first attack when they were less than three years old. Moreover, $71.2 \%$ once suffered respiratory tract infections. For $95.7 \%$ of asthmatic children, the asthma attack was first manifested as cough. Asthmatic children who used inhaled corticosteroids (ICS) only accounted for $46 \%$.

Conclusions: The prevalence of asthma in children aged 0-14 years in Qingdao China increased significantly based on data obtained ten years ago (2000). Respiratory tract infections were the most important precursors of asthma attack. The attack was most commonly manifested as cough. The treatment, especially the use of ICS, was more rational. However, a certain difference was found, which has yet to be contrasted with the Global Initiative for Asthma (GINA) project.

\section{Background}

Asthma in children has become an increasingly remarkable public health problem worldwide. In 1998, an ISAAC article reported that more than $20 \%$ of children once suffered from wheezing in Australia, New Zealand, Oman, Peru, Singapore, and the UK [1]. Additionally, $9.1 \%$ of US children (6.7 million) had asthma in 2007 [2]. As early as 2002, WHO defined asthma as the most common chronic disease in children according to large-scale investigations and analysis [3]. The prevalence of childhood asthma in

\footnotetext{
*Correspondence: linrongjun0312@126.com

'The Affiliated Hospital of Qingdao University, Qingdao 266003, China Full list of author information is available at the end of the article
}

China increased considerably in 1990s, which ranged from $0.93 \%$ in 1990 to $1.54 \%$ in 2000 [4]. In 2000, the prevalence of asthma in Qingdao was 2.67\% [5]. No new investigation has been conducted in the past 10 years. To obtain the newest trends of childhood asthma in Qingdao China, a questionnaire-based survey was performed among 10,082 children, aged $0-14$ years, as respondents.

\section{Methods}

Subject

Our study was conducted in Qingdao, a beautiful coastal city in eastern China with a temperate monsoon climate. Cluster sampling survey method was used. The required 
sample size, calculated with prevalence of $1.54 \%$ in 2000 , included approximately 10,000 subjects. We randomly selected nine schools, seven kindergartens, and three communities in Qingdao to be investigated using the lottery method. Our subjects were the children born between July 1, 1996 and June 30, 2010, which had a total of 10,800 children.

\section{Methods and quality-control measures}

Investigators were doctors or medical students, who were trained before the program. ISAAC and National Epidemiology Study of Asthma and Allergies in China questionnaires were applied in the survey. Two rounds of surveys were launched. First, all the respondents completed the screening questionnaire (ISAAC questionnaire), in which patients suspected of asthma were selected. Second, after the diagnosis by pediatricians in our hospital, asthma patients were asked to complete a second in-depth questionnaire for asthma. A control group that matched the patients was formed to complete a second in-depth questionnaire for non-asthma (National Epidemiology Study of Asthma and Allergies in China questionnaire). In the case of young children, the questionnaires were completed by students or their parents. All the papers were checked by investigators before adoption. The survey started in September 2010 and finished in March 2011.

The following diagnostic criteria of asthma were used: (1) respondents had been diagnosed with asthma by professional pediatricians of three A-grade hospitals and received asthma treatment, or (2) respondents were diagnosed in our hospital using the diagnostic criteria of GINA 2012 [6].

The investigation was performed in accordance with the Declaration of Helsinki and approved by the Medical Ethics Committee of the Affiliated Hospital of Qingdao University. Each questionnaire was approved by the child's guardian.

\section{Data management and analysis}

Data were double entered using epi-info system. Statistical analyses were performed using the SPSS 17.0 software. $\chi 2$ test was applied for data comparison between groups. $\mathrm{P}$ values $<0.05$ were regarded as statistically significant in all analyses.

\section{Results}

\section{Prevalence of asthma in Qingdao}

The prevalence of childhood asthma in Qingdao was $3.69 \%$. Overall, 10,082 children were investigated. Among these children, 373 were diagnosed with asthma. From this group of children, 57 were identified to have cough variant asthma, which accounted for $15.3 \%$. The prevalence in children aged 3-7 was higher than the average. Table 1 shows the prevalence of asthma in different ages.
Table 1 The prevalences of asthma in different ages

\begin{tabular}{cccc}
\hline Age (Year) & Number & Asthma children & Prevalence (\%) \\
\hline$\sim 1$ & 243 & 2 & 0.82 \\
$\sim 2$ & 351 & 12 & 3.42 \\
$\sim 3$ & 344 & 26 & 7.56 \\
$\sim 4$ & 595 & 100 & 16.81 \\
$\sim 5$ & 638 & 61 & 9.56 \\
$\sim 6$ & 650 & 63 & 9.69 \\
$\sim 7$ & 1005 & 43 & 4.28 \\
$\sim 8$ & 701 & 16 & 2.28 \\
$\sim 9$ & 1076 & 14 & 1.30 \\
$\sim 10$ & 705 & 5 & 0.71 \\
$\sim 11$ & 924 & 15 & 1.62 \\
$\sim 12$ & 774 & 7 & 0.90 \\
$\sim 13$ & 915 & 2 & 0.22 \\
$\sim 14$ & 947 & 5 & 0.53 \\
$\sim 15$ & 214 & 1 & 0.47 \\
Total & 10082 & 372 & 3.69 \\
\hline
\end{tabular}

\section{Gender and age difference}

Among the 10,082 respondents, 5,126 were males and 4,956 were females. The ratio of male to female was $1.03: 1$. However, the prevalence of asthma in males was $4.60 \%$, and in females was $2.74 \%$, which shows a clear difference $(\chi 2=24.53, \mathrm{P}<0.01)$.

Age of the first attack and initially diagnosed as asthma Based on first asthmatic attack, the children were divided into three age groups: $<3 \mathrm{y}, 4-6 \mathrm{y}$, and $7-14 \mathrm{y}$. The incidents of first attack were $79.3 \%, 17.7 \%$, and 3\%, respectively. Based on the same grouping, 39.2\%, 56.5\%, and 4.3\% of the children of each group were initially diagnosed as asthmatic.

\section{Precursors of asthma attack}

Asthma attacks in $71.2 \%$ of the asthmatic children were caused by respiratory tract infection. Other precursors included cold air, exercise, eating fish, and smoke, which accounted for $42.2 \%, 28.2 \%, 13.7 \%$, and $9.4 \%$, respectively.

\section{Signs of attack and clinical manifestations}

Runny nose, sneezing, and nasal congestion were identified as the most common signs of asthma attack (63.4\%, $62.9 \%$, and $53.0 \%$, respectively). Table 2 presents the details. In all clinical manifestations, cough was observed on $95.7 \%$ of the patients and $35.8 \%$ of the asthmatic children had cough for more than one month. Other manifestations were wheezing (82.3\%) and suffocation (41.4\%). Table 3 shows every clinical manifestation and its incidence. Most asthmatic children (72.3\%) felt that 
Table 2 Incidence of signs of attack in $\mathbf{3 7 2}$ asthma children

\begin{tabular}{ccc}
\hline Signs & Number & Incidence(\%) \\
\hline Runny nose & 236 & 63.4 \\
Sneezing & 234 & 62.9 \\
Nasal congestion & 197 & 53.0 \\
Itchy noes & 145 & 39.0 \\
Itchy eyes & 99 & 26.6 \\
Itchy throat & 47 & 12.6 \\
Others & 37 & 9.9 \\
\hline
\end{tabular}

the asthma attack was tolerable, but $17.5 \%$ had to visit the emergency room because of severe asthma attacks.

\section{Treatment and economic cost}

Figure 1 shows the high use of quick-relief medications, such as bronchodilators (87.4\%), and low use of preventative medication, such as ICS (46\%). Among the patients, $72.6 \%$ and $69.9 \%$ used anti-allergy medicine and leukotriene modifiers, respectively. Traditional Chinese medicine was used by $6.5 \%$ of the patients. Immunomodulators, theophylline, and desensitization therapy were rarely used. In an acute attack, $29.8 \%$ patients took antibiotics and $10.5 \%$ were given systemic application of steroid.

This disease entailed significant costs for a number of asthmatic children and their families; $71.8 \%$ of the parents spent $¥ 2000-5000$ (approximately \$ 300-750) annually for their asthmatic children; $14.2 \%$ spent less than $\bigotimes 2000$, and $14 \%$ spent more than $¥ 5000$. Nevertheless, almost all parents (99.7\%) expressed their capability to afford the treatments.

Table 3 Incidence of manifestations in $\mathbf{3 7 2}$ asthma children

\begin{tabular}{ccc}
\hline Manifestations & Number & Incidence(\%) \\
\hline Cough & 356 & 95.7 \\
Wheezing & 306 & 82.3 \\
Suffocation & 154 & 41.4 \\
Night waking & 142 & 38.2 \\
Chest tightness & 69 & 18.5 \\
Prolonged expiratory & 68 & 18.3 \\
Dyspnea & 13 & 3.5 \\
Sweat & 5 & 1.3 \\
Orthopnea & 4 & 1.1 \\
Dysphagia & 2 & 0.5 \\
Cyanosis & 1 & 0.3 \\
\hline
\end{tabular}

\section{Discussion}

Possible reasons for high prevalence in Qingdao

After 2000, results of several studies on the prevalence of childhood asthma showed no changes [7-9] or even significant decreases [10,11]. By contrast, more studies indicated an increase in the prevalence [12-16]. Our study agrees with the latter. The prevalence of childhood asthma in Qingdao (3.69\%) was considerably higher compared with the data gathered in 2000 (2.67\%) [5], The trend that was also observed in other Chinese cities [17]. The prevalence of childhood asthma in Qingdao was higher than the national average (3.02\%) [18].

Environmental, climate, and industrial factors may be related to the high prevalence of childhood asthma in Qingdao. First, the moist air in Qingdao, a beach city, provides a good environment for dust mites and mildew, which may be the most important allergens of asthma [19]. Second, Qingdao residents are partial to seafoods, which easily cause allergic disease. Third, the farming environment, which offered protective effect on the development of asthma in children [20], has been affected by the rapid industrialization, which also increased air pollution. The environmental and climate factors definitely contribute to the causes of asthma [21,22]. LIU Yan-li reported that mites were the major allergens, and eating seafoods was an important risk factor for asthmatic children in Qingdao [23]. Additionally, many patients informed us that they felt much better in another city. However, the aforementioned potential reasons require further study. We are working hard to complete such study.

\section{Improvement in diagnosis of asthma}

In recent years, an increasing number of Chinese doctors have become familiar with GINA, which resulted in significant improvement in the diagnosis of asthma. In the survey, $97 \%$ of asthmatic children had their first attack at $<6$ y. Meanwhile, $95.7 \%$ were initially diagnosed with Asthma at $<6$ y. Most (98.7\%) asthmatic children can be inferred to have received accurate diagnosis at the initial period of the disease.

\section{Role of respiratory tract infection in asthma}

Among the asthmatic children, $71.2 \%$ had suffered asthma attack after contracting respiratory tract infection. Clearly, the infection of the respiratory tract had a close relationship with asthma. The possible mechanism was that the pathogen injury of the airway epithelial, which caused the airway to become hyper responsive and induced asthma to occur more easily. Dr. Gern reported that respiratory syncytial virus and rhinovirus were the main viruses causing asthma attacks in infants and older children, respectively [24]. Atypical microorganisms were also reported to influence the occurrence 


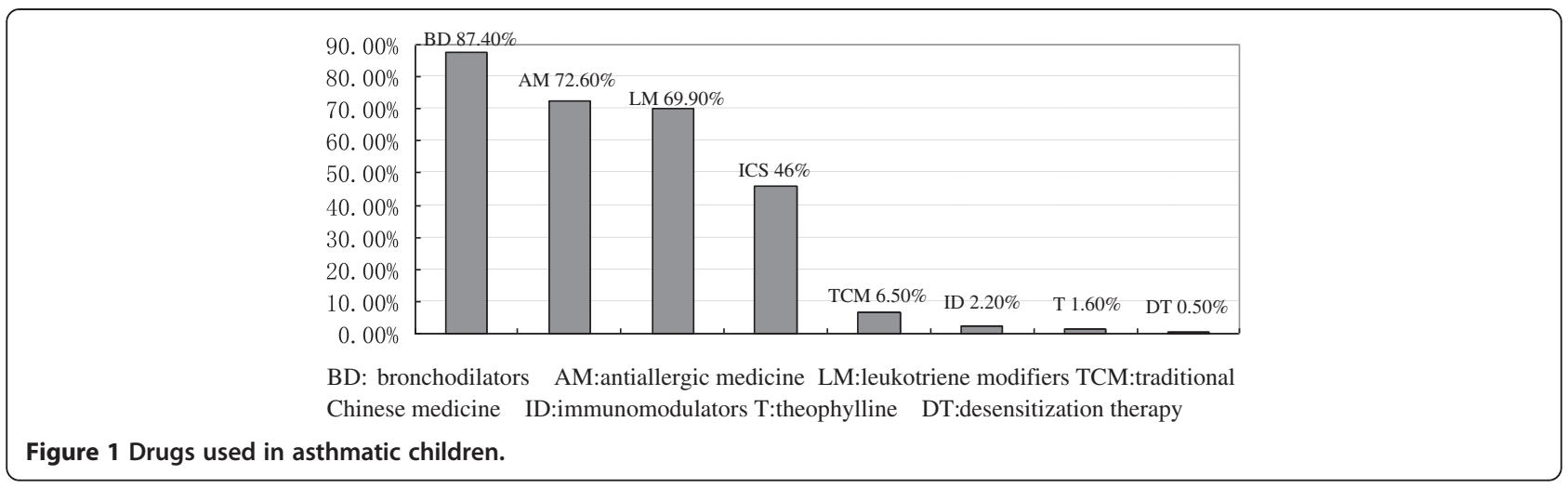

of an asthma attack [25]. Therefore, asthmatic children should be protected from respiratory infection to reduce the risk of asthma attack.

\section{Problems in treatment}

Epidemiological data indicated that asthma control was suboptimal in both developed and developing countries [26-28]. The same problem was also found in our survey. We found that only $46 \%$ of asthmatic children in Qingdao China used ICS, which was the main and basic control medicine for asthma [6]. However, this percentage denotes considerable progress compared with data from 2000 , in which only $19.6 \%$ of asthmatic children used ICS [5]. Compared with the use of bronchodilators (87.4\%), anti-allergy (72.6\%), and leukotriene modifiers (69.9\%), the resistance to the use of ICS was stronger, which may have come from parents. The possibility of steroid-related side effects could be the first reason. $\mathrm{Nu}$ merous parents refused immediately when medicine with steroid was discussed. Other parents put forward the concern on whether ICS would result in a short or unhealthy child. Lack of apparent efficacy may be the second reason. Many parents complained over the uselessness of ICS as proven by the lack of immediate change in the condition of their children. Moreover, bronchodilators quickly transformed the frowns on children's faces to smiles. Based on following observations, we believe economic factors did not play a critical role in the parents' medicine choice. As mentioned earlier, almost all parents expressed their capability to afford the treatments. Moreover, the daily cost of leukotriene modifiers was not lower than that of ICS in China. GINA has proven that ICS is the best medicine for asthma control. A series of research demonstrated that ICS produced minimal side effects [6]. Many parents were worried over the height of their children. In early 2000, the New England Journal of Medicine revealed that inhaling medium or low dose ICS did not affect the height of asthmatic children [29]. Nevertheless, guiding parents and their children toward acceptance of this idea remains a difficult task to accomplish.

\section{Conclusions}

Our survey showed that the present prevalence of asthma in Qingdao is significantly higher compared with its occurrence ten years ago. This observation is consistent with the general trend in China. Thus, childhood asthma, which remains an important public health concern, demands more attention today and in the future. Environmental and industrial changes may have contributed to this trend. Less respiratory tract infection may mean less asthma attack. Despite the increasing reliance on ICS, the fulfillment of this goal seems to have become a more challenging process. Further studies are needed to discern the possible reasons that could fully explain the observation.

\section{Competing interests}

The authors declare that they have no competing interests.

\section{Authors' contributions}

RJL designed and trained all the investors, which included supervision over the administration process. XML, BCZ, JG, and $L L$ distributed the questionnaires and conducted quality-control work. RZG performed statistical analysis and wrote the manuscript. All the authors have read and approved the final manuscript.

\section{Author's information}

Renzheng Guan is co-first author.

\section{Acknowledgements}

We express our gratitude to Yingying Liu, Dongxia Liu, Jianping Guo, and Mei xu. These four students contributed significantly to the study. We thank our colleagues in the community health service centers, schools, and kindergartens, as well as the children and their parents who participated in the program. Without their help, our work would not have been possible.

\section{Author details}

${ }^{1}$ The Affiliated Hospital of Qingdao University, Qingdao 266003, China. ${ }^{2}$ Qingdao Hiser Medical Group, Qingdao 266033, China.

Received: 13 January 2014 Accepted: 7 August 2014

Published: 26 September 2014

\section{References}

1. The International Study of Asthma and Allergies in Childhood (ISAAC) Steering Committee: Worldwide variation in prevalence of symptoms of asthma, allergic rhinoconjunctivitis, and atopic eczema: ISAAC. Lancet 1998, 351:1225-1232. 
2. Akinbami $\sqcup$, Moorman JE, Garbe PL, Sondik EJ: Status of childhood asthma in the United States, 1980-2007. Pediatrics 2009, 123:S131-45.

3. WHO: WHO Strategy For Prevention And Control Of Chronic Respiratory Diseases. In Geneva; 2002. http://www.who.int/respiratory/publications/ crd_strategy/en/.

4. National Cooperation Group on Childhood Asthma: China Comparative analysis of the state of asthma prevalence in children from two nation 2 wide surveys in 1990 and 2000 year. Chin J Tuberc Respir Dis 2004, 27(2):112-116

5. National Cooperation Group On Childhood Asthma: A nationwide survey in China on prevalence of asthma in urban children. Zhonghua Er Ke $\mathrm{Za}$ Zhi 2003, 41(2):123-127.

6. The global strategy for asthma management and prevention, Global Initiative for Asthma (GINA) 2012. Available from: http://www.ginasthma.org/.

7. Braun-Fahrlander C, Gassner M, Grize L, Takken-Sahli K, Neu U, Stricker T, Varonier HS, Wüthrich B, Sennhauser FH, Swiss Study on Childhood Allergy and Respiratory symptoms; Air Pollution (SCARPOL) team: No further increase in asthma, hay fever and atopic sensitization in adolescents living in Switzerland. Eur Respir J 2004, 23:407-413.

8. Lee SL, Wong W, Lau YL: Increasing prevalence of allergic rhinitis but not asthma among children in Hong Kong from 1995 to 2001 (Phase 3 International Study of Asthma and Allergies in Childhood). Pediatr Allergy Immunol 2004, 15:72-78.

9. Ronchetti R, Villa MP, Barreto M, Rota R, Pagani J, Martella S, Falasca C, Paggi B, Guglielmi F, Ciofetta G: Is the increase in childhood asthma coming to an end? Findings from three surveys of schoolchildren in Rome, Italy. Eur Respir J 2001, 17:881-886.

10. Toelle BG, Belousova E, Salome CM, Peat JK, Marks GB: Prevalence of asthma and allergy in schoolchildren in Belmont, Australia: three cross-sectional surveys over 20 years. BMJ 2004, 328:386-387.

11. Anderson HR, Ruggles $R$, Strachan DP, Austin JB, Burr M, Jeffs D, Standring P, Steriu A, Goulding R: Trends in prevalence of symptoms of asthma, hay fever, and eczema in 12-14 year olds in the British Isles, 1995-2002: questionnaire survey. BMJ 2004, 328:1052-1053.

12. Downs SH, Marks GB, Sporik R, Belosouva EG, Car NG, Peat JK: Continued increase of asthma and atopy. Arch Dis Child 2001, 84:20-23.

13. Anthracopoulos M, Karatza A, Liolios E, Triga M, Triantou K, Priftis K: Prevalence of asthma among schoolchildren in Patras, Greece: three surveys over 20 years. Thorax 2001, 56:569-571.

14. Ng Man Kwong GN, Proctor A, Billings C, Duggan R, Das C, Whyte MK, Powell CV, Primhak R: Increasing prevalence of asthma diagnosis and symptoms in children is confined to mild symptoms. Thorax 2001, 56:312-314.

15. Esamai F, Ayaya S, Nyandiko W: Prevalence of asthma, allergic rhinitis and dermatitis in primary school children in Uasin Gishu district, Kenya. East Afr Med J 2002, 79:514-518.

16. Maziak W, Behrens T, Brasky TM, Duhme H, Rzehak P, Weiland SK, Keil U: Are asthma and allergies in children and adolescents increasing? Results from ISAAC phase I and phase III surveys in Mu" nster, Germany. Allergy 2003, 58:572-579.

17. Bai J, Zhao J, Shen $K L$, Xiang L, Chen AH, Huang S, Huang Y, Wang JS, Ye RW: Current trends of the prevalence of children asthma in three Chinese cities:a multicenter epidemiological survey. Biomed Environ Sci 2010, 23(6):453-457.

18. The National Cooperative Group on Childhood Asthma: Third nationwide survey of childhood asthma in urban areas of China. Zhonghua Er Ke Za Zhi 2013, 51(10):729-735

19. Li J, Wang H, Chen Y, Zheng J, Wong GW, Zhong N: House dust mite sensitization is the main risk factor for the increase in prevalence of wheeze in 13- to 14-year-old schoolchildren in Guangzhou city. China Clin Exp Allergy 2013, 43(10):1171-1179.

20. Ege MJ, Mayer M, Normand AC, Genuneit J, Cookson WO, Braun-Fahrländer C, Heederik D, Piarroux R, von Mutius E, GABRIELA Transregio 22 Study Group: Exposure to Environmental Microorganisms and Childhood Asthma. N Engl J Med 2011, 364(8):701-709.

21. Shea KM, Trucker RT, Weber RW, Peden DB: Climate change and allergic disease. J Allergy Clin Immunol 2008, 6:443-453.

22. Kasznia-Kocot J, Kowalska M, Gorny RL, Niesler A, Wypych-Ślusarska A: Environmental risk factors for respiratory symptoms and childhood asthma. Ann Agric Environ Med 2010, 17(2):221-229.
23. LIU Yan-li: Investigate the common causes of asthmatic exacerbation in children with asthma in Qingdao Area. Medical Innovation of China 2013, 10(9):085-087.

24. Gern JE: Viral and bacterial infections in the development and progression of asthma. J Allergy Clin Lmmumol 2000, 105(Suppol):497-502

25. Daian $\mathrm{CM}$, Wolff $\mathrm{AH}$, Bielory L: The role of atypical organisms in asthma. Allergy Asthma Proc 2000, 21(2):107-111.

26. Rabe KF, Vermeire PA, Soriano JB, Maier WC: Clinical management of asthma in 1999: the Asthma Insights and Reality in Europe (AIRE) study. Eur Respir J 2000, 16:802-807.

27. Adams RJ, Fuhlbrigge A, Guilbert T, Lozano P, Martinez F: Inadequate use of asthma medication in the United States: results of the Asthma in America national population survey. J Allergy Clin Immunol 2002, 110(1):58-64.

28. Lai CK, De Guia TS, Kim YY, Kuo SH, Mukhopadhyay A, Soriano JB, Trung PL, Zhong NS, Zainudin N, Zainudin BM, Asthma Insights and Reality in Asia-Pacific Steering Committee: Asthma control in the Asia-Pacific region:the asthma insights and reality in Asia-Pacific study. J Allergy Clin Immunol 2003, 111:263-268.

29. The Childhood Asthma Management Program Research Group: Long-term effects of budesonide or nedocromil in children with asthma. N Engl J Med 2000, 343(15):1054-1063.

doi:10.1186/1471-2458-14-1002

Cite this article as: Lin et al:: Significant rise of the prevalence and clinical features of childhood asthma in Qingdao China: cluster sampling investigation of 10,082 children. BMC Public Health 2014 14:1002.

\section{Submit your next manuscript to BioMed Central and take full advantage of:}

- Convenient online submission

- Thorough peer review

- No space constraints or color figure charges

- Immediate publication on acceptance

- Inclusion in PubMed, CAS, Scopus and Google Scholar

- Research which is freely available for redistribution 